\title{
GÊNERO E VIOLÊNCIA: UMA APROXIMAÇÃO DOS DISCURSOS SOBRE A MULHER NO MỤNO DA CRIMINALIDADE'
}

\author{
GENDER AND VIOLENCE: AN APPROACH OF THE SPEECHES ON THE \\ WOMAN IN THE WORLD OF CRIME
}

Valter Cardoso da Silva ${ }^{2}$ Marilia Gomes de Carvalho ${ }^{3}$

\begin{abstract}
Resumo
O presente trabalho faz parte da pesquisa maior que foi desenvolvida junto ao Programa de pós-graduação em Tecnologia da UTFPR, onde se investiga as concepções de gênero e tecnologia presentes na educação ofertada a adultos reclusos em unidades penitenciárias. Desenvolve-se aqui uma análise dos discursos sobre a mulher no mundo da criminalidade. Os operadores do direito parecem ter tomado por base o já bastante discutido estereótipo que pretende relegar às mulheres o mundo privado, o ambiente doméstico, enquanto que o espaço público, o ambiente da rua, está reservado ao homem. Assim, o mundo da criminalidade é essencialmente masculino, pois exige características de coragem e virilidade, que não se quer reconhecer nas mulheres. Desta forma, os crimes por elas praticados são revestidos de um caráter passional, ocasionado por situações emocionais extremas como o ciúme, a defesa da prole ou, ainda, apoio ao companheiro. Mesmo quando cometem crimes "hediondos", que fogem a estas características, são condenadas muito mais pelo fato de ter fugido à sua natureza dócil e passiva, totalmente instituída no imaginário social, do que pela natureza do crime que cometeram. Nega-se à mulher, também na área da criminalidade, seu papel de sujeito histórico, capaz de escolhas e atitudes, não podendo, portanto, ser totalmente responsabilizada pelos seus atos; logo precisando ser ainda tutelada.
\end{abstract}

Palavras-chave: Gênero, criminalidade, operadores do direito.

\begin{abstract}
The present work is part of the largest research that was developed in association to the Master's Degree in Technology of UTFPR, where the concepts of gender and technology are investigated in the education applied to recluse adults in prisons. This article presents an analyses of speeches on the woman in the world of the crime. The operators of the law seem to have taken as basis for their assignments the so much discussed stereotype that intends to relegate women to the private world and the domestic atmosphere, while the public space and the street atmosphere belong to men. Therefore, the world of the crime is considered essentially masculine, because it demands some characteristics as courage and manliness which the operators don' $t$ recognize in women. This way, the crimes committed by them are related to a passionate character, caused by extreme emotional situations involving jealousy, the defense of the offspring or still to support their companion. Even though they commit very serious crimes, different from these particularities, they are much more condemned for not fulfilling their docile and passive nature, that is totally instituted in the social imaginary, than for the nature of the crime they have committed. In the crime area, it is also denyed to the woman her role as a historical individual capable of making choices and having attitudes. So, she is not considered completely responsible for her acts and still needs to be tutored.
\end{abstract}

Keywords: Gender, criminality, operators of the right. 
O objetivo deste artigo é buscar uma aproximação dos discursos sobre a mulher no mundo da criminalidade. Esta preocupação surge a partir do desenvolvimento de uma pesquisa maior, que está sendo desenvolvida junto ao Programa de Pós-Graduação em Tecnologia da UTFPR, em que se investiga as concepções de gênero e tecnologia presentes na educação ofertada a adultos reclusos em unidades penitenciárias.

Isto porque, procurando tomar contato com textos que dessem embasamento para a compreensão da realidade de homens e mulheres encarcerados, descobre-se que neste universo existe uma divisão de papéis masculinos e femininos com base em estereótipos dicotomizados.

Buscando entender este universo, há que se tomar como ponto de partida que o mundo ocidental, capitalista e globalizado, pode ser caracterizado como multifacetado, plural e com várias possibilidades de compreensão. Neste sentido, o recorte de gênero pode trazer uma importante contribuição para a compreensão deste contexto, uma vez que o mesmo permite a análise de como se processa uma série de fenômenos relevantes no que se refere à dinâmica das relações de poder estabelecidas na sociedade - mais explicitamente, como se consolidam e se estruturam os papéis sociais para homens e mulheres.

Assim, ao procurar estudar e discutir as perspectivas e matizes teóricas capazes de propor categorias que permitissem uma melhor compreensão da subordinação da mulher ao homem - que ocorre em várias partes do mundo e em varias épocas - chega-se ao enfoque das relações de gênero como construção histórica ${ }^{4}$, isto é, como fruto das relações que a sociedade foi construindo ao longo do tempo, na medida em que definia papéis diferenciados para mulheres e homens.

Assim, para a pesquisadora Joan Scott:

a palavra gênero indicava uma rejeição ao determinismo biológico implícito no uso de termos como 'sexo' ou 'diferença sexual'. O termo gênero enfatizava igualmente o aspecto relacional das definições normativas da feminilidade. Aquelas que estavam preocupadas pelo fato de que a produção de estudos sobre mulheres se centrava nas mulheres de maneira demasiado estreita e separada utilizaram o termo 'gênero' para introduzir uma noção relacional em nosso vocabulário analítico. Segundo esta visão, as mulheres e os homens eram definidos em termos recíprocos e não se poderia compreender qualquer um dos sexos por meio de um estudo inteiramente separado (1995, p.73).

A partir daí, propõe-se o uso do gênero como categoria de análise, numa abordagem relacional - isto é, que pretende compreender a dinâmica dos papéis masculinos e femininos a partir das relações estabelecidas historicamente entre os sexos. Este enfoque permite a superação de uma visão parcial e dicotômica - ainda muito presente, por exemplo, no mundo do trabalho - que alimenta representações nas quais as diferenças entre homens e mulheres são de caráter puramente biológico.

Compreende-se, então, porque as posições calcadas em estereótipos, e que, apesar disso, desempenham importante papel na construção das identidades masculinas e femininas, passam - em determinados ambientes sociais, nos quais os agentes buscam de alguma forma outras formas de constituição - a sofrer importantes questionamentos quanto à sua validade.

É o caso, por exemplo, da inserção de homens e mulheres no mundo do trabalho: Pedro (1994) demonstra haver uma separação entre o público e o 
privado, entre o mundo da produção e o ambiente familiar, sendo que os primeiros estariam ligados de modo "natural" ao espaço masculino, e os segundos, da mesma forma, ao espaço feminino.

No entanto, mesmo sendo considerada uma atividade secundária e recebendo uma remuneração inferior a que os homens recebem, a participação das mulheres nas atividades produtivas têm contribuido para que a dicotomia homem/mulher - fruto de uma divisão sexual do trabalho - seja posta em questão.

Essas constatąções dão margem para uma visão da complexidade de modelos assumidos por homens e mulheres dentro de seu contexto social, considerando os vários fatores que influenciam na formação da personalidade dos sujeitos (COSTA, 1994).

De qualquer forma, este discurso dualista descrito acima, que reserva o mundo público como um espaço masculino, deixando o mundo privado e doméstico como espaço a ser ocupado pela mulher, se dissemina socialmente e permeia as relações intersubjetivas constituídas pelos sujeitos.

Assim, numa primeira aproximação, o mundo da criminalidade é visto não apenas pelo leigo em geral, mas principalmente pelos operadores do direito - como masculino. Isto , em primeiro lugar, porque é um espaço público, o que por si só já o interditaria para a atuação feminina. Mas, para além desta interdição, entende-se que este mundo exige características que foram historicamente atribuidas aos homens, tais como arrojamento, agressividade, capacidade de luta e enfrentamento, uma certa brutalidade que - quando se pensa na construção de identidades dos sujeitos no ocidente - parece estar associada à virilidade e ao perfil masculino.

No caso feminino, pelo contrário, sempre se procurou enxergar nelas características opostas às elencadas acima: vê-se na mulher a pureza e a fragilidade, uma certa complacência necessária à maternidade. Aliás, os estereótipos orientam que ela deve ser pura, porque puras são as mães. $\mathrm{E}$, de qualquer forma, a sua sensibilidade não suportaria os horrores que permeiam o mundo do crime.

Esta visão um tanto idílica da mulher se torna hegemônica na sociedade brasileira em um momento histórico bem específico. Ela vem surgir exatamente quando a moral burguesa se impõe às demais construções existentes no País. O texto de Claudia Fonseca (1997) ajuda a iluminar esta situação, quando nos aponta que "ser mulher, mãe e pobre" no Brasil do início do século exigia características muito mais arrojadas que as de rainha do lar.

Rachel Soihet (1997), no seu texto "Mulheres pobres e violência no Brasil urbano", também demonstra que a história desta sujeição feminina ao lar está ligada historicamente ao discurso burguês, o qual associa que o modelo de mulher perfeita, a mulher de bem, a mulher que não será "mal falada" é a mãe submissa, que deverá ficar circunscrita à instância doméstica.

$E$, ainda assim, elas saem desta esfera. Ainda assim, elas continuam a trabalhar. $E$, algumas cometem crimes.

Esta constatação se apresenta um tanto quanto inusitada, já que os estereótipos sobre a mulher apontam a natureza feminina "isenta" do crime. Michele Perrot, no seu estudo sobre os excluídos da história, já ironizava que, em vez de os cometer, "Eva" induz ao crime: "Ainda em nosso dias, 'o detento 
partilha da crença popular de que é ela a instigadora do crime, a causa de todas as suas desgraças'. A mulher, gênio maligno do homem: a literatura criminal participa do mito da eterna Eva" (PERROT, 1992, p. 258).

Os operadores do direito e a literatura criminal em seu discurso têm tomado por base o já discutido estereótipo que pretende relegar às mulheres o mundo privado, o ambiente doméstico, enquanto o espaço público, o ambiente da rua, está reservado ao homem.

Aliás, os criminalistas do século XIX - que estão na base da formação do pensamento juridico e do direito até o presente - já apontavam que as mulheres cometem crimes passionais:

A leitura dos criminologistas sobre o crime cometido pela mulher tem, de certa forma, fundamentação na teoria de Cesare Lombroso, médico e criminalista italiano, o qual assinala que a mulher tem tendência ao homicídio passional, movida pelo ciúme e pela vingança. Para ele essa tendência tem perfeito lugar na mulher prostituta, derivativo criminal das mulheres. A mulher normal, do ponto de vista de Lombroso, é um ser inferior, dada ao instinto e não à inteligência e, portanto, próxima dos selvagens, malvada por índole. A mulher criminosa é ainda mais inferior, pois tem analogia com a estrutura psíquica e física do delinqüente, ou seja, o criminoso nato que se aproxima do monstro pelos traços físicos de regressão da espécie. A mulher é semelhante ao criminoso nato e, embora menos propícia ao crime, também o comete, sendo desviante as prostitutas e as criminosas. (ALMEIDA, 2001, p. 75)

Embora a leitura de autores como Lombroso possa parecer datada e marcada por um certo darwinismo social extremado, Almeida (2001) afirma que, mesmo em nossos dias, existe a tipificação "crime feminino" e que este, no decorrer da história, esteve associado aos crimes de paixão - aqueles cometidos sob forte pressão ou influência emocional - e àqueles que são fruto de distúrbios de ordem biológica - como o infanticídio cometido no período puerperial.

Existe, também, a idéia de que a mulher só se envolve com a criminalidade no papel de cúmplice, isto é, teria sido levada a se envolver no universo da criminalidade por um parente próximo - o pai ou o filho - ou ainda por seu companheiro - namorado, marido ou amante. Estaria categorizado então seu papel de coadjuvante. Assim, no mundo da criminalidade, a mulher não seria considerada um sujeito ativo.

Neste ponto algumas reflexões sobre o discurso se fazem necessárias. Até que ponto esta forma de observar a mulher não se configura como estratégia de dominação? Voltando ao texto de Michele Perrot, seria preciso assumir suas indagações:

O crime, o delito são assuntos de homens, atos viris cometidos na selva das cidades. Seu esvanecimento nesse teatro será o indice de sua submissão, de uma moralização ampliada da mulher? Ou uma certa forma de afastá-la para os bastidores? Essa indulgência, no fundo não será suspeita? Recusar à mulher sua estrutura criminal não será ainda uma maneira de negá-la? (PERROT, 1992, p.256-258).

Há que se discutir: seriam as condições hormonais especificas do corpo feminino - como por exemplo, as já populares tensões pré-menstruais - que realmente induzem a mulher a comportamentos violentos? Ou, seriam as 
condições histórico-sociais de repressão impostas à mulher que só the deixariam esta forma específica, este momento único de rebeldia e liberação? Passado tal período, estaria ela novamente obrigada a retornar a seu cotidiano de submissão?

Acrescente-se a esta reflexão a situação dos crimes hediondos aqueles que envolvem altas doses de frieza e premeditação, aqueles que fogem totalmente à tipificação de "crime feminino" - como, por exemplo, um dos casos citado por Almeida (2001) em seus estudos, o seqüestro seguido da morte de uma criança.

Numa situação como essa, o crime é severamente castigado. Neste caso, as mulheres são condenadas mais pela destituição de sua natureza dócil, instituída no imaginário social, do que pelo crime propriamente dito.

Mas, outras indagações surgem aqui. As mulheres podem ter os mesmos tipos de vivências e reações que os homens? Uma mulher pode ser tão fria e calculista quanto um homem? $\mathrm{O}$ uso da racionalidade voltada para a criminalidade se constituiria em atributo estritamente masculino? Em suma, a mulher é capaz de cometer e praticar os mesmos tipos de crimes que os homens? Ou deve ainda continuar sendo alvo de uma suposta benevolência masculina dos operadores do direito?

Almeida parece ter a resposta sobre a questão dos crimes femininos: "O tratamento penal deve ser o mesmo dado ao homem, porque a sansão deve ser equivalente ao delito praticado e não proporcional ao sexo de quem o procedeu" (ALMEIDA, 2001, p. 98). Afinal, negar à mulher, também na área da criminalidade, seu papel de sujeito histórico capaz de escolhas e atitudes, não podendo, portanto ser totalmente responsabilizada pelos seus atos, é uma maneira de mantê-la ainda sob tutela.

\section{Referências}

ALMEIDA, Rosemary de Oliveira. Mulheres que matam. Rio de Janeiro: Relume Dumará, 2001.

CASAGRANDE, Lindamir S. \& CORREA, Ronaldo O. Definindo Gênero. Disponível em: http://www.ppgte.cefetpr.br/genero. Acesso em 07/08/2004.

COSTA, Claudia de Lima. O leito de Procusto: gênero, linguagem e as teorias femininas. Cadernos Pagu, vol. 2, 1994.

FONSECA, Claudia. Ser mulher, mãe e pobre. In: PRIORE, Mary Del (org). História das mulheres no Brasil. São Paulo: Contexto, 1997.

PEDRO, Joana Maria. Mulheres honestas e mulheres faladas: uma questão de classe. Florianópolis: UFSC, 1994.

PERROT, Michelle. Os excluídos da história: operários, mulheres, prisioneiros. $2^{a}$ ed. Rio de Janeiro: Paz e Terra, 1992.

SCOTT, Joan. Gênero: Uma categoria útil de análise histórica. Educação e realidade, Porto Alegre, v.20, n. 2, p. 71-99, jul-dez 1995.

SOIHET, Rachel. Mulheres pobres e violência no Brasil urbano. In: PRIORE, Mary Del (org). História das mulheres no Brasil. São Paulo: Contexto, 1997. 
Notas:

1 O presente trabalho foi apresentado oralmente no evento Seminário Internacional Fazendo Gênero 6, em Florianópolis (GT Gênero e violência), ocorrido na UFSC em agosto de 2004.

2 Mestre em Tecnologia - PPGTE/UTFPR (Cefet-pr); professor de Filosofia, Sociologia e História; pesquisador de GeTec/UTFPR e do CESPDH/UFPR.

3 Pós-Doutora pela Université de Technologie de Compiègne - França; Doutora em Antropologia Social - USP; Professora do Programa de Pós-Graduação em Tecnologia - PPGTE, da Universidade Tecnológica Federal do Paraná - UTFPR; Coordenadora do Grupo de Estudos e Pesquisas sobre Relaçōes de Gênero e Tecnologia - GeTec.

4 Utiliza-se neste artigq a categoria gênero como apresentada por Scott, isto é fruto das relaçōes de poder constituidas historicamente entre homens e mulheres. No entanto, existem várias outras leituras que entendem o gênero como variável binária; gênero como papéis sexuais dicotomizados; gênero como uma variável psicológica, gênero como tradução de sistemas de culturas. Para uma aproximação maior a estas outras formas de interpretaçăo da categoria ver CASAGRANDE e CORREA (2004), e ainda COSTA (1994). 